\title{
Familial idiopathic pulmonary fibrosis in association with bone marrow hypoplasia and hepatic nodular regenerative hyperplasia: a new "trimorphic" syndrome
}

\author{
A Talbot-Smith, ${ }^{1}$ W-K Syn, ${ }^{2}$ G MacQuillan, ${ }^{3}$ D Neil, ${ }^{2}$ E Elias, ${ }^{2}$ P Ryan ${ }^{1}$
}

${ }^{1}$ Department of Respiratory Medicine, Hereford County Hospital, Hereford, UK; ${ }^{2}$ Liver Unit, Queen Elizabeth Hospital, Birmingham, UK; ${ }^{3}$ Sir Charles Gairdner Hospital, Perth, Western Australia, Australia

Correspondence to: Dr A Talbot-Smith, Department of Respiratory Medicine, Hereford County Hospital, Hereford HR1 2ER, UK;

alistalb@hotmail.com

Received 21 April 2008 Accepted 14 September 2008

\section{ABSTRACT}

This is the first report of familial idiopathic pulmonary fibrosis associated with hepatic nodular regenerative hyperplasia and bone marrow hypoplasia. Four members of one family presented with this triad of organ dysfunction. The response to immunosuppressive treatment was poor and all four members succumbed to the disease processes. The current literature is reviewed and mechanisms that could have been involved in the development of this new syndrome are proposed.

We report the first case of familial idiopathic pulmonary fibrosis (FIPF) associated with hepatic nodular regenerative hyperplasia (NRH) and bone marrow hypoplasia. We have named this "trimorphic syndrome"-three (inherited) morbidities, pulmonary, hepatic and cytopenia.

\section{CASE HISTORY}

\section{Sibling 1}

A 34-year-old man presented with a 3-week history of cough and dyspnoea. He had no medical history, had never smoked and worked as a builder/ carpenter. He was clubbed, had harsh breath sounds throughout both lung fields and hepatosplenomegaly. The chest radiograph showed illdefined nodules throughout both lung fields. Pulmonary function tests (PFT) and high-resolution CT (HRCT) scan of his chest were consistent with pulmonary fibrosis (table 1 ).

The serum angiotensin-converting enzyme (ACE) level was normal. He was thrombocytopenic but bone marrow examination was normal (table 2). Liver enzymes were mildly raised (table 2), while ultrasonography demonstrated diffusely abnormal liver architecture and portal hypertension. A full liver and autoimmune screen (autoantibodies, immunoglobulins, viral hepatitis $B$ and $C$ serology, $\alpha_{1}$-antitrypsin, caeruloplasmin, celiac serology) was negative. Serum ferritin was mildly elevated (507 $\mu \mathrm{g} / \mathrm{l}$, normal range 15-300), but haemochromatosis gene (C282Y/H63D) mutation analysis was negative.

He deteriorated clinically and was commenced on high-dose prednisolone. Repeat bone marrow examination showed hypocellularity (table 2). He underwent a transjugular liver biopsy but deteriorated during the procedure and died (10 months after presentation). Post-mortem examination (tables 1 and 2) confirmed pulmonary fibrosis and NRH (fig 1).

\section{Father}

Five months later the 74-year-old father, a retired bricklayer, presented with a 4-month history of dyspnoea. Examination revealed inspiratory crepitations. PFTs were consistent with pulmonary fibrosis, while the HRCT scan showed fibrosis and pleural thickening (table 1). He was thrombocytopenic but liver enzymes were normal (table 2). Serum autoantibodies (nuclear and ANCA) were negative, with minimal elevation of serum ACE (59 IU/1, normal range 9-50).

He failed to attend appointments and died suddenly 18 months later. Post-mortem examination confirmed IPF (table 1), portal hypertension, $\mathrm{NRH}$ (table 2) and mild myocardial fibrosis.

\section{Sibling 2}

Four years after sibling one presented, his 46-yearold brother presented with a 12-month history of cough and dyspnoea. He had never smoked and worked as a bricklayer. Examination revealed bibasal inspiratory crepitations. PFTs and HRCT scan were consistent with IPF, which was

Table 1 Pulmonary features at presentation by person

\begin{tabular}{llllll}
\hline & PFTs & TLco (\% predicted) & HRCT chest & Lung histology \\
\hline Sibling 1 & Restrictive pattern & 43 & Widespread fibrosis and honeycombing & Pulmonary fibrosis* \\
Father & Restrictive pattern & 33 & Fibrosis and pleural thickening & IPF* $^{*}$ \\
Sibling 2 & Restrictive pattern & 49 & Widespread fibrosis and honeycombing & IPF + pleural plaques $\dagger^{*}$ \\
Sibling 3 & Normal limits & 78 & Patchy fibrotic change consistent & IPF* $^{*}$
\end{tabular}


Table 2 Haematological and hepatic features at presentation by person

\begin{tabular}{|c|c|c|c|c|c|}
\hline & $\begin{array}{l}\text { Platelets } \\
\left(\times 10^{\circ} / \mathrm{l}\right)\end{array}$ & Bone marrow & $\begin{array}{l}\text { Liver function } \\
\text { tests }\end{array}$ & Liver histology & $\begin{array}{l}\text { Portal } \\
\text { hypertension }\end{array}$ \\
\hline Sibling 1 & 38 & $\begin{array}{l}\text { Normal with some increased } \\
\text { metamyelocytes thought to be } \\
\text { secondary to hypersplenism, } \\
\text { progressing to hypocellular }\end{array}$ & Mildly elevated & $\begin{array}{l}\text { Hepatic nodules with } \\
\text { compression of sinusoids and } \\
\text { atrophy of hepatocytes at } \\
\text { edges* }^{*}\end{array}$ & Yes $\dagger$ \\
\hline Father & 98 & Not done & Normal & $\begin{array}{l}\text { Hepatic nodules and sclerotic } \\
\text { portal tracts, small/absent portal } \\
\text { veins, incomplete septal } \\
\text { fibrosis* }\end{array}$ & Yes $^{*}$ \\
\hline Sibling 2 & 73 & $\begin{array}{l}\text { Hypocellular with areas } \\
\text { suggestive of early secondary } \\
\text { fibrosis }\end{array}$ & Mildly elevated & $\begin{array}{l}\text { Hepatic nodules, small portal } \\
\text { veins close to portal tracts in } \\
\text { areas, shunt vessels in others* }\end{array}$ & Yes* \\
\hline Sibling 3 & 87 & $\begin{array}{l}\text { Low normal cellularity } \\
\text { progressing to } \\
\text { hypocellularity§ with patchy } \\
\text { areas suggestive of early } \\
\text { secondary fibrosis }\end{array}$ & $\begin{array}{l}\text { Normal progressing } \\
\text { to mildly elevated }\end{array}$ & $\begin{array}{l}\text { Sclerotic portal tracts, small/ } \\
\text { absent portal veins, incomplete } \\
\text { septal fibrosis. Hepatocyte } \\
\text { nodules with sinusoidal } \\
\text { compression and dilation* }\end{array}$ & Yes: \\
\hline
\end{tabular}

after presentation.

confirmed by surgical lung biopsy (table 1). He was thrombocytopenic with a hypocellular bone marrow (fig 2), with areas of increased reticulin suggestive of early secondary fibrosis. Liver enzymes were mildly elevated (table 2). Serum ACE, rheumatoid factor, serum autoantibodies and liver screen were negative.

Despite treatment with prednisolone and azathioprine, he died 6 months after presentation. Post-mortem examination revealed IPF (table 1), hepatic NRH (table 2), pleural plaques and mild cardiac fibrosis.

\section{Sibling 3}

An asymptomatic brother aged 57 years was referred alongside sibling 2. He had never smoked and worked as a carpenter/ joiner. Examination revealed scattered bi-basal inspiratory crepitations. PFTs were normal but HRCT of his chest was consistent with IPF (table 1). He was thrombocytopenic with low to normal marrow cellularity but normal liver function tests (table 2). Rheumatoid factor and autoantibodies were

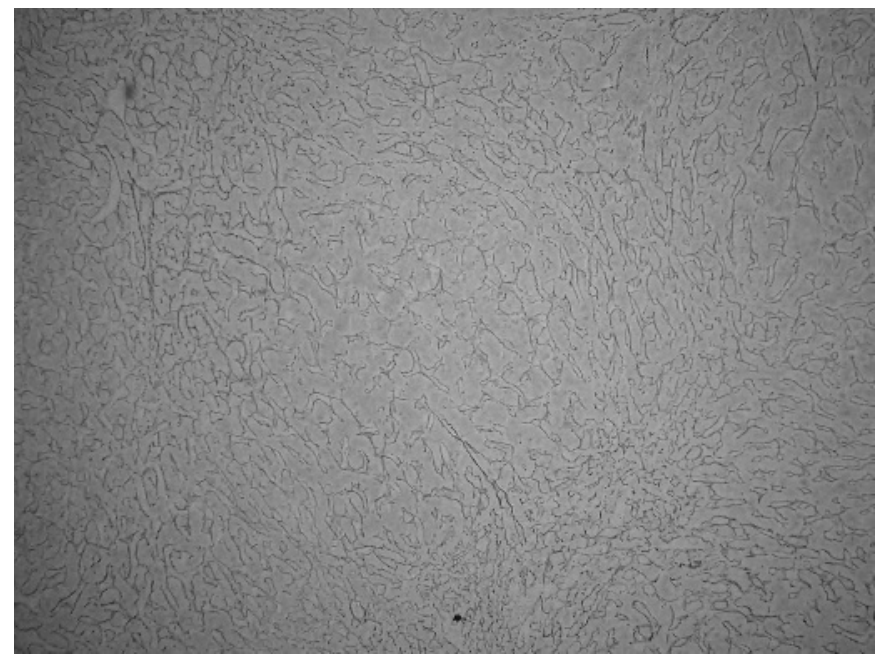

Figure 1 Liver biopsy showing a nodule of larger hepatocytes surrounded by compressed hepatocytes (reticulin stain, $\times 2$ objective lens). negative, while the serum ACE level was mildly elevated (84 IU/ 1, normal range 9-50).

Despite treatment with prednisolone and azathioprine, his lung function deteriorated. He developed raised liver enzymes despite cessation of azathioprine, with ultrasonography showing a shrunken liver and portal hypertension (table 2). A liver screen was negative but the ferritin level was raised $(942 \mu \mathrm{g} / \mathrm{l}$, normal range 15-300); he was negative for haemochromatosis gene mutations (C282Y/H63D). Repeat bone marrow examination showed worsening hypocellularity with areas suggestive of early fibrosis (table 2). He died 4 years after presentation; postmortem examination showed IPF (fig 3) and NRH (table 2).

\section{DISCUSSION}

This is the first report of FIPF associated with hepatic NRH and bone marrow hypoplasia-a combination of fibrotic (lung) and non-fibrotic (liver and bone marrow) processes.

FIPF is defined as at least two members of a biological family (parent, child, sibling) with clinical features of IPF confirmed

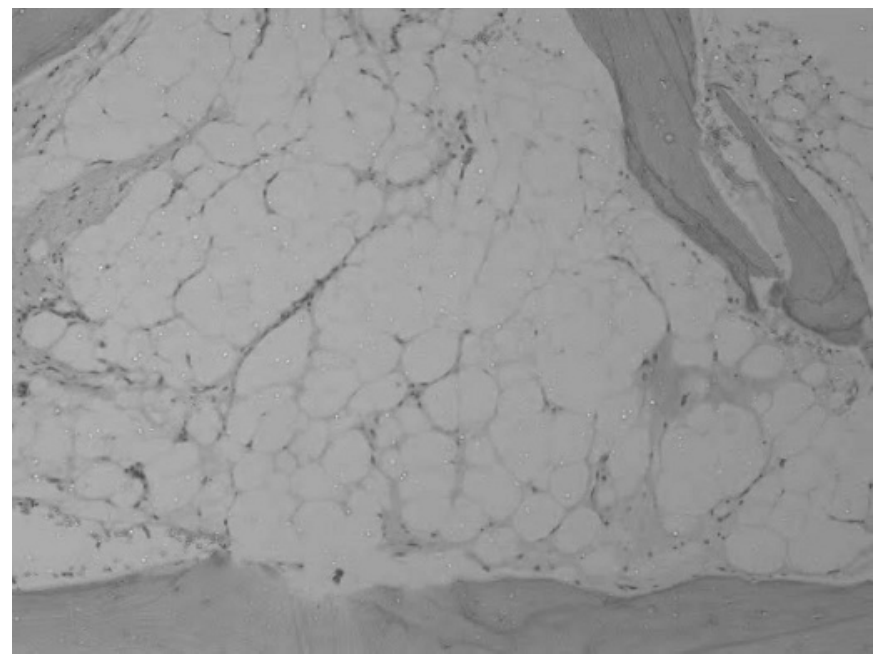

Figure 2 Marrow trephine biopsy showing excess fat spaces with reduced haemopoietic precursors indicative of a hypoplastic marrow (H\&E stain, $\times 20$ objective lens). 


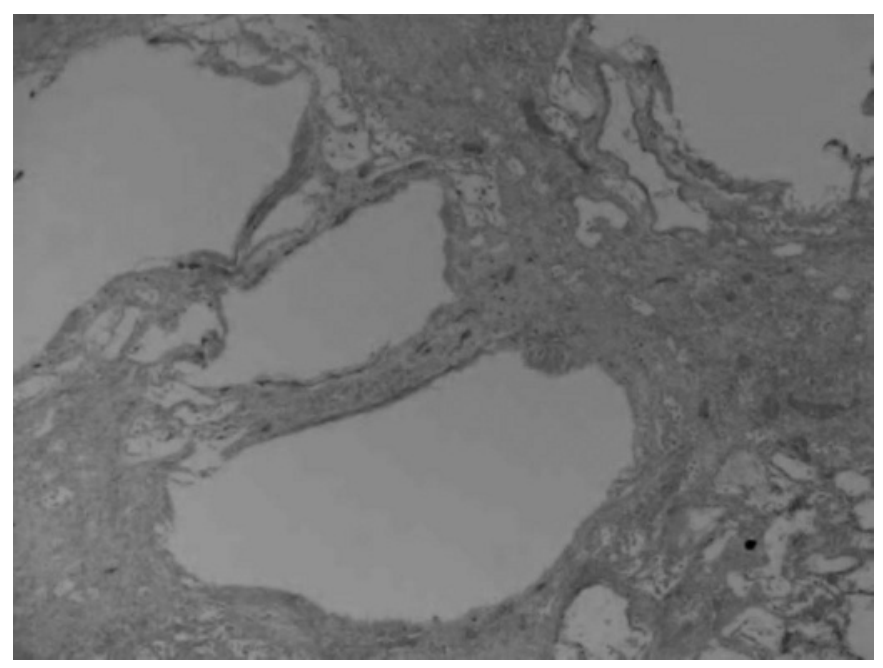

Figure 3 Post-mortem lung tissue showing complete loss of normal alveolar architecture, marked interstitial fibrosis, squamous metaplasia and smooth muscle hypertrophy (H\&E stain, $\times 20$ objective lens).

histologically. ${ }^{1}$ Its prevalence is 1.34 cases per million UK population, accounting for $0.5-2.2 \%$ of cases of $\mathrm{IPF}^{2}$ It is autosomal dominant with variable penetrance, ${ }^{3}$ as in this case with three (out of four) siblings and a parent affected. The earlier age of onset in the index generation may represent genetic anticipation, although their offspring aged between 12 and 29 years remain asymptomatic (fig 4). It is possible that a paternal uncle who died in his 30s from a "liver" condition and a paternal aunt who died in her 70s from aplastic anaemia demonstrated mainly the hepatic and haematological elements of the syndrome.

FIPF has similar clinical features and survival rates to sporadic IPF; ${ }^{4}$ in this family all affected individuals demonstrated a poor response to treatment and poor survival. The phenotypic heterogeneity typical of FIPF $^{5}$ is also demonstrated here; siblings 1 and 2 had widespread fibrotic lung disease while sibling 3 had patchy disease in a distribution more typical of IPF (table 1).

The aetiology of FIPF is poorly understood. Within families it is associated with male sex and cigarette smoking ${ }^{5}$-all our cases were male but none had ever smoked. It is thought to be caused by interaction between a gene (or genes) and an environmental trigger. ${ }^{5}$ All our cases had worked in the building trade and two as carpenters, with exposure to wood dust associated with IPF. ${ }^{6}$ Two had also handled asbestos which can cause pulmonary fibrosis similar to IPF. Neither of these occupational exposures, however, provides a causal link to the hepatic and haematological abnormalities.

In sporadic IPF it is believed that micro-insults to alveolar epithelial cell walls are followed by aberrant wound healing, with fibroblasts depositing extracellular matrix in the distal air spaces. ${ }^{7}$ A number of cytokines, growth factors and other cell mediators are involved in this process, ${ }^{8}$ one or more of which must have systemic actions since bone marrow-derived fibrocytes are recruited to the lungs in IPF. ${ }^{10}$ Such systemic actions could explain the more widespread fibrotic process seen in family members with cardiac and marrow fibrosis and be responsible for the hepatic and haematological abnormalities seen in this family.

Hepatic NRH is characterised by hepatocellular nodules in the absence of fibrous septa between these nodules. Its main complication is portal hypertension. Occurring in $5.6 \%$ of individuals over 80 years, ${ }^{11}$ it is commonly associated with vasculitc conditions, neoplastic and haematological illnesses and drugs including azathioprine. ${ }^{12}$ Two of the cases received azathioprine but one already had abnormal liver enzymes when it was started.

Tissue ischaemia is believed to play an important role in its pathogenesis. ${ }^{13-16}$ In celiac disease IgA anticardiolipin antibodies are thought to trigger thromboses in portal vein radicles draining the small intestine, leading to liver damage and NRH. ${ }^{17}$ Such pathogenic factors might "spill over" into the lungs when the hepatic filtration system fails; interestingly, local activation of the coagulation cascade has been demonstrated in lung models of IPF. ${ }^{18}$ However, siblings 1 and 3 had normal anticardiolipin levels and neither had the common thrombophilia risk factors (gene mutations for factor V Leiden and prothrombin and functional deficiencies of protein C, protein $\mathrm{S}$ and antithrombin III). We are also unable to explain the haematological findings seen in our patients on the basis of such a hypothesis.

Bone marrow hypoplasia is a reduction in the number of haemopoietic progenitor cells in the marrow. It can be congenital, such as in Fanconi's anaemia, or be acquired
Figure 4 Family tree of familial idiopathic pulmonary fibrosis (FIPF) associated with bone marrow hypoplasia and hepatic nodular regenerative hyperplasia. Shading represents affected cases.

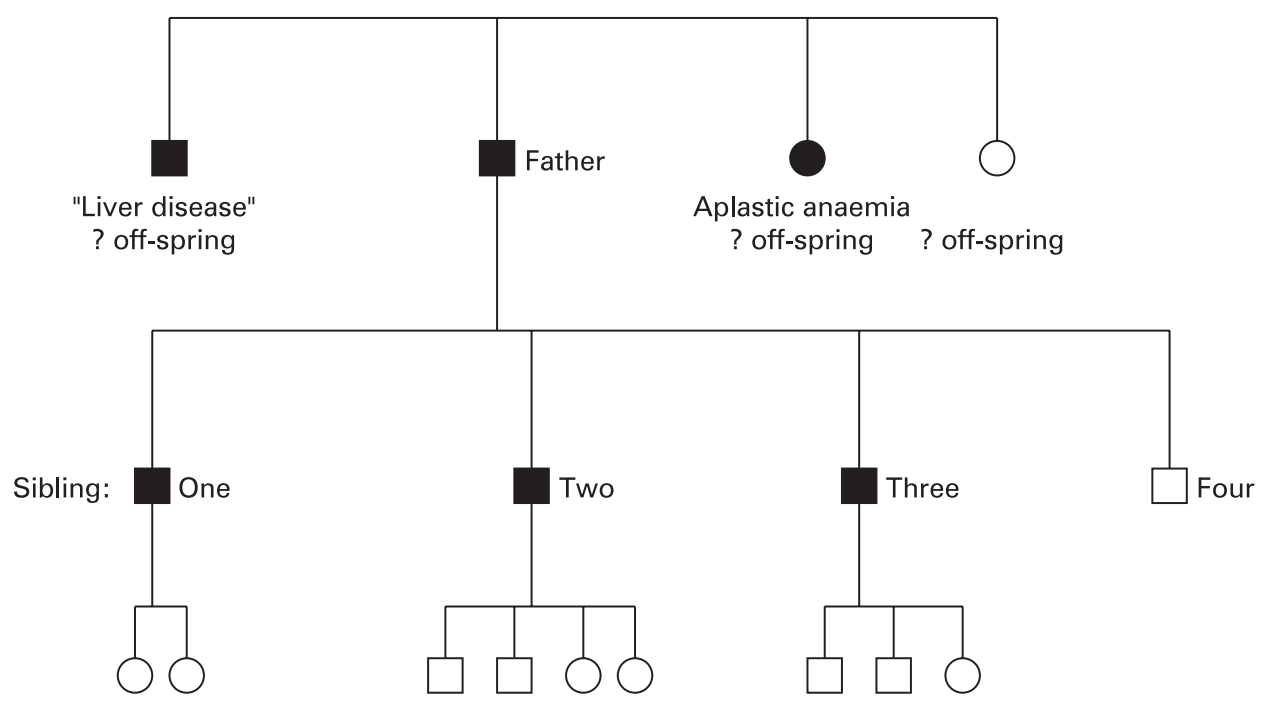


secondary to radiation, viral infections, ${ }^{19}$ drugs $^{20}$ and immunemediated conditions such as systemic lupus erythematosus. ${ }^{21}$ It can be seen in myelofibrosis where marrow is replaced by fibrous tissue. Features typical of myelofibrosis were not, however, seen in these cases; in contrast, mild patchy fibrosis was seen postdating the hypocellularity.

Patients with NRH often present with thrombocytopenia, thought to be secondary to platelet consumption within hepatic thrombi or to undiagnosed hypersplenism from portal hypertension. However, they would be expected to develop a hyperplastic marrow rather than the hypoplastic marrow seen in our cases.

Sibling 2 was thrombocytopenic when he underwent a minor surgical procedure 18 months before presentation (platelets $\left.98 \times 10^{9} / 1\right)$. This might suggest that a bone marrow-derived factor or the absence of a factor normally secreted by the marrow is responsible for both the hepatic and lung pathologies, perhaps causing liver microvascular congestion and nodule formation (ie, NRH) and lung fibrosis through local activation of coagulation cascades. However, such mechanisms remain speculative.

In summary, we have described a new syndrome of familial lung fibrosis, bone marrow hypoplasia and hepatic NRH. Although no unifying pathological process has been identified, we have discussed putative factors. As there are no known genotypic markers for FIPF, screening of the remaining family members is limited to phenotype surveillance. We have offered the remaining sibling and future offsprings of the index generation 5-yearly chest radiography, full blood count and ultrasound scan of the liver. Treatment options, however, remain limited as all affected members have demonstrated a poor response to medical treatment.

Acknowledgements: The authors thank Dr S Willoughby, Consultant Haematologist at Hereford County Hospital for her help with the manuscript and the digital images, and Dr M Hayes, Consultant Histopathologist at Hereford County Hospital for his help with the digital images.

Competing interests: None.

Patient consent: Obtained from relatives of the patients.

\section{REFERENCES}

1. American Thoracic Society. Idiopathic pulmonary fibrosis: diagnosis and treatment. International consensus statement. Am J Respir Crit Care Med 2000;161:646-64.

2. Marshall RP, Puddicombe A, Cookson WOC, et al. Adult familial cryptogenic fibrosing alveolitis in the United Kingdom. Thorax 2000;55:143-6.

3. Bitterman PBSI, Rennard BA, Keogh MD, et al. Familial idiopathic pulmonary fibrosis. Evidence of lung inflammation in unaffected family members. $N$ Engl $\mathrm{J}$ Med 1986;314:1343-7.

4. Lee HA, Ryu JH, Wittner MH, et al. Familal idiopathic pulmonary fibrosis. Clinical features and outcome. Chest 2005;127:2034-41.

5. Steele MP, Speer M, Loyd JE, et al. Clinical and pathological features of familial interstitial pneumonia. Am J Respir Crit Care Med 2005;172:1146-52.

6. Hubbard R, Lewis S, Richards K, et al. Occupational exposure to metal or wood dust and aetiology of cryptogenic fibrosing alveolitis. Lancet 1996;347:284-9.

7. Selman M, Pardo A. The epithelial/fibroblastic pathway in the pathogenesis of idiopathic pulmonary fibrosis. Am J Respir Cell Mol Biol 2003;29(Suppl 3):S93-7.

8. Grutters J, du Bois R. Genetics of fibrosing lung diseases. Eur Respir J 2005;25:915-27.

9. Phillips R, Burdick M, Hong K, et al. Circulating fibrocytes traffic to the lungs in response to CXCL 12 and mediate fibrosis. J Clin Invest 2004;114:438-46.

10. Mehrad B, Burdick M, Zisman D, et al. Circulating peripheral blood lymphocytes in human fibrotic interstitial lung disease. Biochem Biophys Res Commun 2007;353:104-8.

11. Wanless I. Micronodular transformation (nodular regenerative hyperplasia) of the liver: a report of 64 cases among 2,500 autopsies and a new classification of benign hepatocellular nodules. Hepatology 1990;11:787-97.

12. Gonzalez-Huezo MS, Villela LM, Zepeda-Florencio Mdel C, et al. Nodular regenerative hyperplasia associated to aplastic anaemia: a case report and literature review. Ann Hepatol 2006;5:166-9.

13. Wanless IR, Godwin TA, Allen F, et al. Nodular regenerative hyperplasia of the liver in hematologic disorders: a possible response to obliterative portal venopathy. A morphometric study of nine cases with an hypothesis on the pathogenesis. Medicine 1980:59:367-79.

14. Wanless IR, Mawdsley C, Adams R. On the pathogenesis of focal nodular hyperplasia of the liver. Hepatology 1985;5:1194-200.

15. Shimamatsu K, Wanless IR. Role of ischemia in causing apoptosis, atrophy, and nodular hyperplasia in human liver. Hepatology 1997;26:343-50.

16. Wanless IR, Solt LC, Kortan P, et al. Nodular regenerative hyperplasia of the liver associated with maroglobulinaemia. A clue to the pathogenesis. Am J Med 1981;70:1203-9.

17. Austin A, Campbell E, Lane $\mathrm{P}$, et al. Nodular regenerative hyperplasia of the liver and coeliac disease: potential role of IgA anticardiolipin antibody. Gut 2004;53:1032-4.

18. Chambers R. Procoagulant signalling mechanisms in lung inflammation and fibrosis: novel opportunities for pharmacological intervention. Br J Pharmacol 2008;153(Suppl 1):S367-78.

19. Young N, Mortimer P. Viruses and bone marrow failure. Blood 1984;63:729-37

20. Rosenthal R, Blackman A. Bone marrow hypoplasia following use of chloramphenicol eye drops. JAMA 1965;191:136-7.

21. Feng $\mathbf{C}, \mathrm{Ng} \mathrm{M}$, Szeto $\mathrm{R}$, et al. Bone marrow findings in lupus patients with pancytopenia. Pathology 199;23:5-7. 